\title{
MORFOLOGIA DO FRUTO E DA SEMENTE DE PAU-FERRO Caesalpinia leiostachya Ducke ${ }^{1}$
}

\author{
Martinho Alves de Andrade Júnior (2) \\ José Elias Gomes de Lima (3) \\ Daniel Duarte Pereira (4) \\ Genaro Viana Dornelas (4) \\ José Eduardo Machado dos Santos \\ Antonio Alves de Lima (5)
}

\begin{abstract}
RESUMO - Foram visualizadas as características morfológicas do fruto e da semente de pau-ferro Caesalpinia leiostachya Ducke, em laboratório, descrevendo-se suas respectivas estruturas externas e internas, tais como: epicarpo, mesocarpo, endocarpo, hilo, testa, endosperma, embrião, cotilédones, eixo hipocótilo-radícula e plúmula.

Palavras-chave: Pau-ferro; Caesalpinia leiostachya; Morfologia.

ABSTRACT - Were visualizeds the characteristics morphological of the fruit and seed of pau-ferro Caesalpinia leiostachya Ducke, in laboratory, described yours respectives estrutural external and internal, such as: epicarp, mesocarp, endocarp, hile, forehead, endosperm, embryo, cotyledon, axle hypocotil-radicule and plumule.
\end{abstract}

Key words: Pau-ferro; Caesalpinia leiostachya; Morphology.

1 Parte da Dissertação de Graduação do primeiro autor

2 Eng $^{\circ}$ Agr $^{\circ}$ do MIRR

3 Acadêmico do curso de Agronomia da UFPB

4 Prof. do curso de Agronomia da UFPB

5 Eng $^{\circ}$ Agr $^{\circ}$ da UFPB

Bol. Mus. Int. de Roraima, Boa Vista, 3 (1): 5-8, jul. 1995 


\section{INTRODUÇÃO}

Vários fatores, físicos e fisiológicos, influenciam a variabilidade da forma e tamanho dos frutos e sementes. A caracterização das estruturas externas e internas, assim como o próprio tamanho dessas estruturas, é indispensável para que se possa conhecer melhor uma determinada espécie de planta, assim como, segundo Araújo (1994), além de facilitar a identificação é importante também no estudo de mecanismo de dispersão e regeneração.

Singh, citado por Alves \& Prazeres (1980), menciona que não se tem mostrado interesse bastante na descrição de forma externa, tamanho, cor, textura, ornamentação da superfície, posicão do hilo, da micrópila e da rafe da semente.

Este trabalho objetiva fornecer informações a respeito da morfologia do fruto e da semente do pau-ferro.

\section{MATERIAL E MÉTODO}

Este estudo foi desenvolvido no Herbário Jayme Coelho de Moraes do Centro de Ciências Agrárias, Campus III da Universidade Federal da Paraíba, localizado no município de Areia (PB).

As características externas do fruto de pau-ferro foram descritas através de visualização a olho nu. Em seguida, com auxílio de uma tesoura de poda, procedeu-se a abertura dos frutos para visualização interna das estruturas e conseqüente descrição das características do epicarpo, mesocarpo e endocarpo.

As sementes caracterizadas foram amostradas, ao acaso, em número de 20 e colocadas em água fervente por um período de 20 minutos aproximadamente. Em seguida, com auxílio de uma lupa binocular de marca Wild Heerbrugg e de uma lâmina cirúrgica tipo bisturi, foram realizados cortes longitudinais e transversais que permitiram a visualização das características estruturais externas e internas das sementes. Também foi efetuada a visualização externa da semente ao natural, sem nenhum tratamento prévio.

\section{RESULTAdOS}

O fruto do pau-ferro C. leiostachya é um legume, polispérmico, indeiscente, glabro, crasso, achatado, oblongo de ápice mucronado e base obtusa, tortuoso e de superfície rugosa. Mede em média 7,93 cm de comprimento e 3,55 cm de largura. O epicarpo é de coloração marrom-escura e de natureza lenhosa, apresentando uma espessura média de 0,8 mm. 0 mesocarpo apresenta uma consistência subcarnosa, formado por uma polpa esponjosa de cor marrom-claro. O endocarpo é lenhoso, com uma espessura média de 1,6 mm, com sinuosidade originando câmaras monospérmicas. Em média, cada fruto apresenta 6,0 câmaras (Figs. 1-3).

Bol. Mus. Int. de Roraima, Boa Vista, 3 (1) : 5-8, jul. 1995 


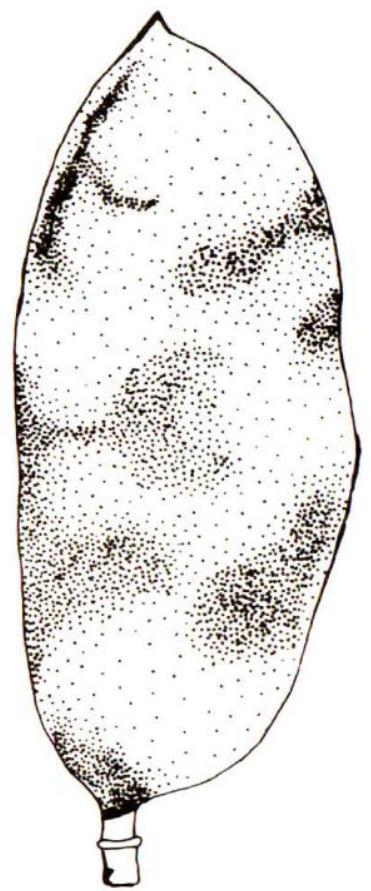

1

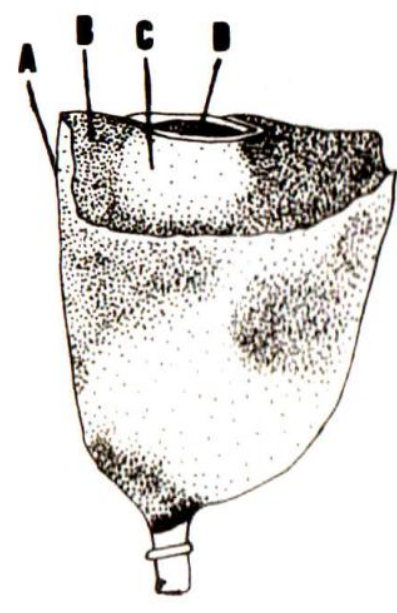

2

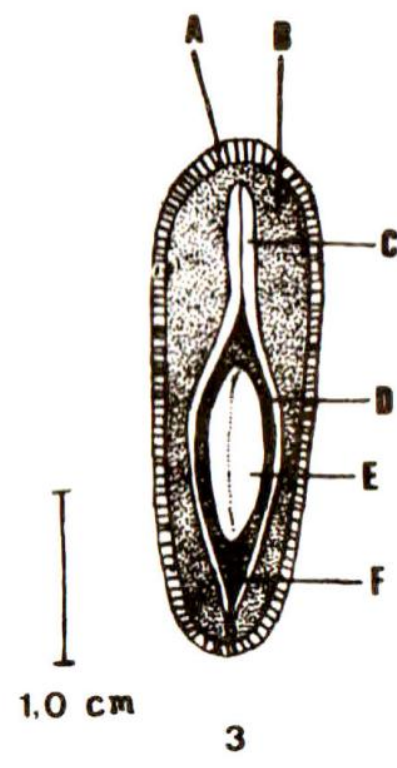

3

Figuras 1-3. Caesalpinia leiostachya: fruto; 1, visualização externa; 2. visão lateral em corte transversal: epicarpo (a), mesocarpo (b), endocarpo (c), câmara espermática (d); 3, corte transversal:

epicarpo (a), mesocarpo (b), endocarpo (c), câmara espermática (d), semente (e), funículo (f).

A semente possui formato oblongo de ápice mais ou menos cuneiforme, de coloração marrom-escura. Apresenta rugosidade e estrias arqueadas. Mede em média cerca de 0,97 cm de comprimento, 0,61 cm de largura e 0,48 cm de espessura. O hilo é puncteiforme, testa coriácea, endosperma delgado e cartilaginoso, embrião reto, axial do mesmo formato da semente, com cotilédones foliáceos e carnosos de coloração amarelo-fechada. Eixo hipocótilo-radícula mais ou menos cilíndrico, localizado entre os dois cotilédones, apresentando dilatação no terço inferior (próximo à radícula). Plúmula conspícua de forma romboidal com rudimentos foliares franjados (Figs. 4-8).

Bol. Mus. Int. de Roraima, Boa Vista, 3 (1): 5-8, jul. 1995 


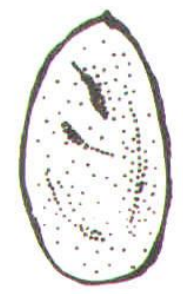

$I$

$0,5 \mathrm{~cm}$

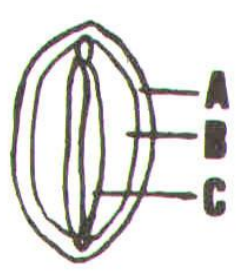

5

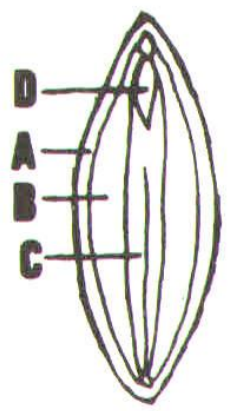

6

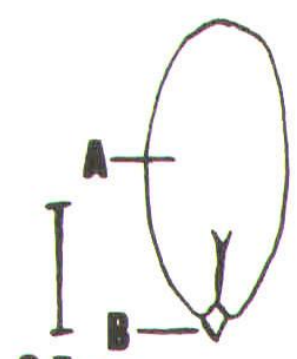

$0,5 \mathrm{~cm}$

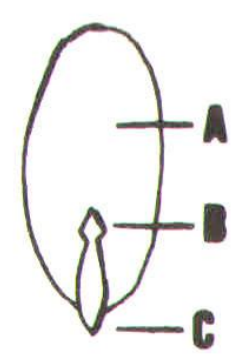

8

Figuras 4-8. Caesalpinia leiostachya: semente; 4, visualização externa; 5, corte transversal: casca (a), endosperma (b), cotilédones (c); 6, corte longitudinal: casca (a), endosperma (b), cotilédones (c), radícula (d); 7, embrião dissecado: cotilédones fechados (a), radícula (b) ; 8, embrião dissecado: cotilédone aberto (a), plúmula (b), radícula (c).

\section{BIBLIOGRAFIA}

-ALVES, José Luiz de Hamburgo \& PRAZERES, Severino do Monte. Estudo da morfologia e fisiologia da germinação da semente de plantas ocorrentes em região de caatinga. Brasil Florestal, Brasília, (44): 85-94, 1980.

-ARAÚJO, Mariângela de. Efeitos de quebra de dormência na germinação e produção de mudas de embiridiba Buchenavia tomentosa. Areia, Universidade Federal da Paraíba, 1994. 49p. (Dissertação de Graduação).

-CORREA, Manoel Pio. Dicionário das Plantas úteis do Brasil: e das exóticas cultivadas. Rio de Janeiro, IBDF, 1984. 6 il. v5.

-FIGLIOLIA, Márcia Balistiero \& AGUIAR, Ivor Bergemann. Colheita de Sementes. In: AGUIAR, Ivor Bergemann, et al. Sementes Florestais Tropicais. Brasília, ABRATES, 1993.cap.7: 275-302, 350p.

-HERINGER, Ezechias Paulo. Contribuição ao conhecimento da flora da zona da mata de Minas Gerais. Bol. do Serv. Nac. de Pesqui. Agron. Rio de Janeiro, (2): 141-142, 1947.

Recebido em 02/05/95

Aprovado em $10 / 06 / 95$

Bol. Mus. Int. de Roraima, Boa Vista, 3 (1): 5-8, jul. 1995. 